\title{
Trachea Cartilage
}

National Cancer Institute

\section{Source}

National Cancer Institute. Trachea Cartilage. NCI Thesaurus. Code C49304.

One of a variable number of incomplete, C-shaped cartilaginous rings encircling the anterolateral portion of the trachea, which are horizontally stacked and separated by narrow intervals throughout the length of the trachea. 